\title{
Produção de Conhecimento \& Aprendizagem Socioprática em Cidades Amazônicas: uma análise da Gestão Social no Observatório Social de Belém
}

Knowledge Production \& Sociopractical Learning in Amazon Cities: an analysis of Social Management at the Social Observatory of Belém/Brazil

\author{
Júnia Fátima do Carmo Guerra ${ }^{1}$ \\ Ana Maria Vasconcellos ${ }^{2}$ \\ Armindo dos Santos de Sousa Teodósio ${ }^{3}$
}

\section{Resumo:}

Este artigo tem como objetivo analisar a produção de conhecimento na Gestão Social construída no âmbito do Observatório Social de Belém (OSB). Para tanto, foram discutidas as premissas teóricas sobre Gestão Social apoiadas na ideia de cidades justas, democráticas e sustentáveis, bem como a produção de conhecimento a partir da noção de aprendizagem socioprática, por considerar que este tipo de conhecimento permeia as práticas e as dinâmicas do Observatório Social de Belém e envolve a participação social, princípio da Gestão Social. Os resultados derivados da pesquisa qualitativa demonstraram que a produção de conhecimento nessa iniciativa do campo da Gestão Social promovida pelas práticas e interações realizadas no OSB se dá em espaços de discussão, de diálogo e de embates, os quais induzem a reflexão entre os atores envolvidos no contexto de cidades justas e sustentáveis. Porém, observou-se que, apesar da consistência das parcerias e interações firmadas com alguns grupos da sociedade civil e setores públicos há, por vezes, informações pouco disseminadas, o que torna o diálogo menos qualificado e traz grandes desafios para a produção de conhecimento compartilhada. Além disso, notou-se que há uma lacuna entre o setor empresarial e a sociedade civil mais vulnerável, de forma que esses segmentos pouco contribuem para a consolidação de cidades justas e sustentáveis.

Palavras-chave: Produção de Conhecimento; Aprendizagem Socioprática; Observatório Social; Cidades; Belém.

\footnotetext{
Abstract:

${ }^{1}$ Doutora em Administração (PUC Minas). E-mail: junia.guerra@uemg.br

2 E-mail: anamaria.vasconcellos@unama.br

3 Professor do Programa de Pós-Graduação Stricto Sensu em Administração (PPGA) da Pontifícia Universidade Católica de Minas Gerais (PUC Minas). Pesquisador das áreas de Gestão Social e Ambiental, Políticas Públicas e Estudos Organizacionais. Líder do Núcleo de Pesquisas em Ética e Gestão Social (NUPEGS) do PPGA da PUC Minas. Seus interesses de pesquisa concentram-se em Organizações da Sociedade Civil, Movimentos Sociais, Responsabilidade Socioambiental de Empresas, Políticas Públicas e Desenvolvimento Sustentável. Doutor em Administração de Empresas pela Escola de Administração de Empresas de São Paulo (EAESP) da Fundação Getúlio Vargas (FGV), Mestre em Ciências Sociais (Gestão de Cidades) pela PUC Minas e Graduado em Ciências Econômicas pela Universidade Federa de Minas Gerais (UFMG). E-mail: armindo.teodosio@gmail.com
} 
This article aims to analyze the production of knowledge in Social Management built within the Social Observatory of Belém (OSB). Therefore, the theoretical premises of Social Management supported by the idea of fair, democratic and sustainable cities were discussed, as well as the production of knowledge from the notion of socio-practical learning, considering that this type of knowledge permeates the practices and dynamics of Social Observatory of Belém and involves social participation, a principle of Social Management. The results derived from the qualitative research showed that the production of knowledge in this initiative in the field of Social Management, promoted by the practices and interactions carried out at the OSB, takes place in spaces for discussion, dialogue and debates, which lead to reflection among the actors involved in the context. of fair and sustainable cities. However, it was observed that, despite the consistency of the partnerships and interactions established with some groups of civil society and public sectors, there is sometimes little disseminated information, which makes the dialogue less qualified and brings major challenges for the production of shared knowledge. In addition, it was noted that there is a gap between the business sector and the most vulnerable civil society, so that these segments contribute little to the consolidation of fair and sustainable cities.

Keywords: Knowledge Production; Sociopractical Learning; Social Oberservatory; Belém/Brazil.

\section{Introdução}

O presente artigo tem como objetivo central discutir a produção de conhecimento no âmbito do Observatório Social de Belém, no contexto da busca pela promoção das chamadas Cidades Justas, Democráticas e Sustentáveis. Tal experiência de inovação social, pelos pressupostos participativos e orientados para a promoção do interesse público no âmbito das cidades, assume características de uma iniciativa do campo da Gestão Social.

O Observatório Social de Belém (OSB) é uma Organização da Sociedade Civil de Interesse Público (OSCIP), que objetiva o fortalecimento do controle social por meio de duas linhas de ação: (1) a conscientização e a mobilização da população apoiados em programas de educação fiscal e (2) ao estímulo à participação de jovens no desenvolvimento local justo e sustentável, bem como no acompanhamento dos gastos públicos (Venturini, 2013). O OSB associa-se a Rede Nossa Belém (RNB) que, por sua vez, vinculase a Rede Social Brasileira por Cidades Justas e Sustentáveis (RSB). Essa última tem a missão de apoiar, estimular, propor e executar, de forma apartidária, inter-religiosa e democraticamente participativa, ações que visem ao desenvolvimento de uma cidade justa e sustentável (movimentonossabelem.blogspot.com).

O OSB, RNB e RSB são redes sociais que atuam por meio de ações coletivas de cunho sociopolítico na tentativa de viabilizar a organização das demandas da população (Ghon, 2008). Essas ações se dão de forma distinta, no qual se observa atos relacionados à simples denúncias, mobilizações, passeatas e negociações (Ghon, 2011; Lüchmann, Schaefer, Nicoletti, 2017; Pleyers, 2018) até proposições de ajustes em programas e políticas públicas. Atualmente, os atos e ações se evidenciam e se manifestam por via de redes sociais locais, regionais, nacionais e internacionais, utilizando de meios de comunicação e informação virtual (Ghon, 2011; Lüchmann, Schaefer, Nicoletti, 2017; Porta, 2020), o que permite, de alguma forma, a produção de conhecimento. Elas se apoiam em valores que ampliam a qualidade de vida e uma distribuição 
mais justa dos benefícios sociais da economia local (Machado, 2007; Ghon, 2008; Pereira, 2010; Ghon, 2011; Lüchmann, Schaefer, Nicoletti, 2017; Pleyers, 2018; Porta, 2020). Nota-se, a partir de sua institucionalização, que elas "adquiriram um papel-chave como ator político em um Estado democrático, pela importância reconhecida como portador legítimo e representante dinâmico de reivindicações de diferentes setores da sociedade civil" (Machado, 2007, p. 259).

Tal cenário assume características constitutivas de iniciativas, estratégias e práticas do campo da Gestão Social pelo fato de seus processos e finalidades se fundamentarem em dinâmicas e práticas apoiadas na participação democrática e na emancipação social. Essa perspectiva fomenta a aprendizagem sócioprática, que se ancora na dimensão social compartilhada (Cançado, Tavares, Dallabrida, 2013; Lüchmann, Schaefer, Nicoletti, 2017; Gianella, 2018; Porta, 2020). O conhecimento produzido, embora possa ser verificado e analisado no campo individual e psicológico, se fundamenta em processos sociais (Bauman, 2008; Schommer \& Boullosa, 2010; Moraes \& Andion, 2018). Essa ideia deve-se ao fato de se observar uma busca de integração de conhecimentos já existentes com as dinâmicas sociais, políticas, econômicas e culturais que envolvem os atores no processo de ensino-aprendizagem (Easterby-Smith e Araujo, 2001; Lave \& Wenger, 1991). A partir dessa vertente interpretativa, a produção de conhecimento ocorre simultaneamente às relações desenvolvidas entre atores de campos diferentes que, ao interagirem por meio da convergência e/ou divergência de ideias, induz a reflexão e a transformação de significados (Albareda, 2018; Moraes \& Andion, 2018). Nesse contexto, acredita-se que as redes sociais e as organizações da sociedade civil, especificamente o OSB, possibilita a aprendizagem e a produção de conhecimento em espaços que se diferem dos espaços tradicionais de reprodução de conhecimento formal (Santos, 2006; Santos, 2007). Ao promoverem a interação de atores de diferentes esferas sociais no intuito de conduzirem suas ações de fiscalização e de mobilização com foco em cidades justas e sustentáveis, se observa perspectivas de participação, diálogo, confrontos, negociação e reflexão, o que incide na ressignificação sociopolítica das cidades (Harvey, 2008; Agier, 2015).

Tais aspectos orientaram a pergunta de pesquisa deste estudo: como tem ocorrido a produção de conhecimento sobre Gestão Social sob o ideário de cidades justas e sustentáveis no âmbito do OSB?

Por se tratar da análise da produção de conhecimento no campo da Gestão Social, essa pesquisa permeia o campo subjetivo de ação. Mediante esse aspecto optou-se pela pesquisa qualitativa como epistemologia e metodologia estruturantes da investigação cujos instrumentos de coleta de dados se deram por meio de pesquisa documental, entrevistas semiestruturadas com quatro membros do Observatório Social de Belém e observação não participante em eventos organizados pela Rede Nossa Belém no período de outubro a novembro de 2015.

Este artigo, além da introdução, se estruturou da seguinte forma: a primeira sessão aborda as premissas temáticas sobre Gestão Social apoiadas na ideia de cidades justas e sustentáveis. A sessão seguinte discute a produção de conhecimento sobre Gestão Social a partir da noção de aprendizagem socioprática, por considerar que este tipo de conhecimento permeia as práticas e as dinâmicas do OSB. Adiante, são apresentadas as estratégias metodológicas e a análise dos dados coletados. E, por fim, se discute os resultados encontrados, demonstrando que a produção de conhecimento sobre Gestão Social promovida pelas práticas e interações do OSB se dá em espaços de interação, discussão, diálogo e embates, os quais induzem a reflexão entre os atores envolvidos no contexto de cidades justas e sustentáveis. Porém, observase que, apesar da consistência das parcerias e interações firmadas com alguns grupos da sociedade civil e setores públicos há, por vezes, informações pouco disseminadas, o que torna o diálogo menos qualificado. Além disso, nota-se que há uma lacuna entre o setor empresarial e a sociedade civil mais vulnerável com o OSB, de forma que esses segmentos pouco contribuem para a consolidação de cidades justas e sustentáveis. 


\section{Gestão Social: caminhos que convergem para cidades justas e sustentáveis}

A Gestão Social surgiu em um contexto marcado por uma sociedade fragmentada e permeada de grupos excluídos, empobrecida e com riscos ecológicos (Chanlat, 1999; Dowbor, 1999). Frente aos graves problemas afrontados, urgiu a necessidade de se ampliar os horizontes dos aspectos propriamente humanos, de forma que, a dimensão social do desenvolvimento deixou de ser um complemento, para se tornar um dos componentes essenciais da transformação social (Chanlat, 1999, Dowbor, 1999). A ideia de centralidade do sujeito nas esferas sociais converge com os propósitos da Gestão Social em valores e ações fundadas na democracia e cidadania, tendo em vista, o enfrentamento às expressões da questão social, da garantia dos direitos humanos universais e da afirmação dos interesses e espaços públicos como padrões de nova civilidade (Dowbor, 2008).

Mesmo sendo um tema recentemente explorado no cenário brasileiro, e por estar associado às temáticas relativas às transformações do tecido social, observa-se que ele pode se relacionar aos atores sociais que a empregam, ao universo organizacional em que é exercido, às finalidades que se pretende atingir ou, ainda, às características do processo de gestão a que se refere (Schommer e França-Filho, 2008). Esses aspectos permitem convergir a Gestão Social às práticas e dinâmicas sociais territoriais, entendida como desenvolvimento social, local ou de poder local (Abramovay, 2000; Fischer, 2002; Dowbor, 2016).

Para Tenório, Dutra e Magalhães (2004), o desenvolvimento local passou a constituir-se em processo estruturado a partir dos próprios atores locais, enfatizando ações de desenvolvimento com vocações e apelo local, e não mais pelo planejamento centralizado. Neste cenário, observa-se que os processos de desenvolvimento local implicam esforços articulados de atores estatais e da sociedade civil dispostos a levar adiante projetos que surjam da negociação de interesses, inclusive divergentes e em conflitos (Allebrandt, Marin Filho, Ceratti, 2012).

Estas combinações fomentam práticas cooperativas que incluem, evidentemente, a conquista de bens públicos como educação, saúde, informação capazes de enriquecer o tecido social de certa localidade (Abramovay, 2000; Vargas \& Guedes, 2021). A partir dessa ideia e em consonância com Tenório (1999), defende-se a necessidade de construção de uma sociedade descentralizada e caracterizada por espaços públicos que sirvam para identificar e solucionar problemas sociais. "Estes espaços de poder público devem compartilhar com a sociedade civil os interesses da comunidade por meio de um procedimento argumentativo, caracterizado pela cidadania deliberativa" (Tenório, 1999, p.237).

Tal perspectiva vai ao encontro com as prerrogativas da Constituição Federal Brasileira de 1988 que estabelece novos princípios de fortalecimento dos municípios por meio da descentralização. "Esse modelo de gestão pública confere poderes à administração local na definição de políticas próprias e gerenciamento de seus recursos" (Allebrandt, Marin Filho, Ceratti, 2012, p. 285). Com a descentralização, as políticas sociais direcionadas para a saúde, educação, assistência social, meio ambiente e alívio da pobreza, por exemplo, são pensadas e planejadas no âmbito do município. Há uma revalorização do governo e das comunidades locais, criando-se novos arranjos sociais baseados no tripé população, território e organização (Allebrandt, Marin Filho, Ceratti, 2012; Spink \& Spink, 2017).

Esses arranjos não, necessariamente, precisam ser pensados e articulados a partir da iniciativa do Estado e nem por canais de participação social definido por ele. Existe uma variedade de ação e mobilização social oriunda da sociedade civil que busca participar da construção de projetos sociais por meio de redes e movimentos sociais em âmbito local e nacional. Nestes espaços nota-se o importante papel dos movimentos sociais que, segundo Machado (2007 p. 258) refere-se às maneiras de "organização e articulação baseada em um conjunto de interesses e valores comuns, cujo objetivo é definir e orientar as formas de atuação 
social". O autor ainda destaca que esse objetivo busca, a partir de processos, por vezes não institucionais de pressão, "mudar a ordem social existente, ou parte dela, de forma a influenciar os resultados de processos sociais e políticos que envolvem valores ou comportamentos sociais" (Machado, 2007 p. 256). Numa perspectiva de direitos humanos ancorados em uma sociedade democrática é que se formam os movimentos sociais, conduzidos pela livre escolha política no qual cada ator social luta simultaneamente pelo bem comum e pela defesa de interesses particulares (Machado, 2007).

A atuação em redes é um aspecto que se destaca nos movimentos sociais. Segundo Ghon (2011, p. 336) elas "constituem e desenvolvem o chamado empowerment de atores da sociedade civil organizada à medida que criam sujeitos sociais para a atuação em rede". Essa, por sua vez, projeta em seus participantes sentimentos de pertencimento social, formando identidades antes dispersas em grupos desorganizados (Ghon, 2011; Merlucci, 1996). Em uma perspectiva histórica, a autora observa que as redes sociais têm contribuído para organizar e conscientizar a sociedade acerca de questões que envolvem a urgência das necessidades básicas, bem como questões de cunho ideário civilizatórias os quais buscam a construção de uma sociedade democrática (Ghon, 2011). Tais aspectos envolveriam processos cujo cerne se apoiaria no homem enquanto sujeito social e não em instrumento de interesse econômico. Este sujeito social se manifestaria em "espaços que é o lugar praticado ou lugar comum" como expressa Certeau (1998, p. 60). Lugar este que se configura em ambientes de interações, de embates, apoiados no senso comum, na cultura popular e não somente na sua forma estruturante sustentada a partir do lócus da reprodução da força de trabalho, da indústria e da luta de classes assim como observa Castells (1998), ao tentar "compreender as motivações para as agitações e conflitos no espaço urbano" (Santos, 2016. P. 76).

Destaca-se que a ideia de cidades e sua concepção têm sido debatidas pela produção científica internacional há algum tempo (Lefebvre, 1970; Castells, 1977; Harvey, 1982; Kornberg \& Carter, 2010). Contudo, no presente estudo se buscou abordar a ideia de cidades como "espaços sociais estratégicos no qual se percebe uma ampla gama de operações de caráter político, econômico, cultural e subjetivo" (Sassen, 2007 p.7).

Nessa vertente, Lefebvre (1970) observa que as lutas urbanas devem ir além da disputa pelos bens de consumo coletivo, almejando a possibilidade do direito a cidade para que as necessidades humanas possam se manifestar de forma ampla (Santos, 2016). Casimiro e Carvalho (2021, p. 201) ao citarem Saule Júnior (1999) defendem que "as cidades, feitas por pessoas e para as pessoas, deve ser administrada com foco na garantia de qualidade de vida para todos e todas". E para fomentar a noção de cidade de direito cunhada por Lefebvre (1969) é preciso defender que a condição de vida nas cidades requer transformações nas relações entre sociedade e o Estado, cientes da necessidade de "intervenções que tragam vantagens e inconvenientes a serem repartidos entre os diversos segmentos sociais, individual e coletivamente, implicando em um dever público de assumir responsabilidades pautadas em valores como solidariedade, cidadania e democracia participativa" (Casimiro e Carvalho, 2021, p. 202). É nesse sentido que se compreende a urgência da justiça e da sustentabilidade das cidades como mecanismos para mitigar as desigualdades sociais que aprofundam a exclusão no sentido humano e espacial.

A partir deste cenário, entende-se que as redes sociais engajadas na defesa do direito a cidades justas e sustentáveis atuam por meio do diálogo, divergências e convergências, não expressando somente as lutas de classes e a urbanização como um processo social em si mesmo. Essas buscam construir novos significados para a justiça social e a liberdade, ao associá-la ao princípio de inserção autônoma do sujeito na sociedade, redefinindo a esfera pública (Ghon, 2011). A concepção de coletividade e bem comum se baseia em ações democráticas mais substantivas que procuram por meio do controle social dos poderes públicos, da elaboração de ferramentas de conhecimento e monitoramento sobre a qualidade de vida nos municípios (Machado, 2007), espaços de construção colaborativa entre os diversos atores sociais. Tal espaço, assim como apregoa Certeau (1998), se configuraria em um ambiente socialmente produzido, dialético, no qual se reproduz e produz as invenções do cotidiano. 
Essa perspectiva demonstra "contribuir para a formação de uma nova relação entre Estado e sociedade, em que se dissemina a conviç̧ão da ética, da co-responsabilidade sobre aquilo que é de interesse público, envolvendo múltiplos atores na gestão da cidade" (Pereira, 2010 p. 5).

As iniciativas que se inscrevem no âmbito da Gestão Social se aproximam deste cenário ao evidenciar a centralidade do ator social nos processos e fins que têm como propósito o bem comum e a coletividade, cuja integração convergente, divergente e por vezes conflituosa, contribui para os processos de produção de conhecimento.

A fim de contribuir para tal discussão, a seguinte sessão aborda os fundamentos da aprendizagem socioprática como possibilidade de produção de conhecimento em contextos onde há incidência da Gestão Social, como o caso em análise, que compõe uma das iniciativas da Rede Brasileira de Cidades Justas, Democráticas e Sustentáveis.

\section{Aprendizagem Socioprática \& Gestão Social}

A concepção de aprendizagem social ou socioprática parte do princípio que a aprendizagem se constitui como resultado de interações e práticas compartilhadas pelas pessoas, manifestando-se nos comportamentos cotidianos. Dessa forma, apreende-se que, para compreender a aprendizagem, mais importante do que analisar processos cognitivos individuais, é perceber contextos culturais e sociais dos quais as pessoas interagem, constroem suas práticas compartilhadas, seus repertórios cognitivos e emocionais (Schommer, Boullosa, 2010).

Nesse âmbito, a percepção de aprendizagem configurada na prática social considera a prática não como oposta da teoria ou de reflexão, mas como práxis, de ação e reflexão permanentemente imbricadas, sempre em relação a um contexto em que faz sentido para o praticante (Freire, 1987). "Ler, ouvir, pesquisar, parar, aquietar-se, refletir sobre o que foi vivido, sistematizar conhecimento, tudo isso faz parte do processo de aprendizagem" (Schommer e Boullosa, 2010 p. 21).

Leff (2006, p. 310) corrobora essa perspectiva ao argumentar que o conhecimento se "desloca para os efeitos entre o saber e o ser em um processo de reapropriação do mundo", contribuindo para transformação e significação da realidade vivida. Gohn (2011), seguindo essa mesma linha de pensamento, destaca a educação não formal, principalmente aquela oriunda dos movimentos sociais como um meio propício e rico de produção de saberes, no qual as experiências atuais alicerçadas por um passado dão sentido às lutas do presente.

Entretanto, esse processo não se realiza em um "contexto livre de modelagem" (Schommer e Boullosa, 2010 p. 21). Pelo contrário, a abordagem social ressalta que a aprendizagem acontece no seio das estruturas sociais e culturais, enfatizando a interdependência relacional entre sujeito, mundo, atividade, significado, cognição, aprendizagem e conhecimento. Este, num mundo socialmente constituído, é mediado pelo contexto histórico que o cerca e que se apresenta aberto para as mudanças (Lave e Wenger, 1991).

Além dessa perspectiva, Silva (2004, p. 145) argumenta que o conhecimento é constituído por "informação, que é relativamente estável ou estática, em completo relacionamento com características mais subjetivas presente na mente das pessoas". É de cunho dinâmico, ao envolver experiências, contexto, interpretação e reflexão. Tais aspectos denotam duas partes constituintes do conhecimento intrinsecamente relacionados, o conhecimento subjetivo e o conhecimento explícito. O primeiro pode ser identificado pelas habilidades inerentes a uma pessoa; sistemas de ideias, percepção e experiência. O segundo ao ser formalizado em textos, gráficos, tabelas, figuras, desenhos, facilmente organizado em bases de dados e em publicações em 
geral, se apresenta de forma relativamente simples de codificar, de transferir e reutilizar (Nonaka \& Takeuchi, 1997).

Marteleto e Ribeiro (1997) ampliam essa perspectiva ao relacionar os conceitos sobre conhecimento, informação e comunicação. Para as autoras "uma informação relevante ou correta é aquela capaz de gerar um conhecimento sustentado que, por sua vez, supõe a sua comunicação transparente, gerando novas informações e novos conhecimentos" (Marteleto e Ribeiro, 1997 p. 3).

Compreende-se que essa ideia se traduz nas possibilidades de conhecimento geradas no âmbito das Redes Sociais por Cidades Justas, Democráticas e Sustentáveis, sobretudo dos Observatórios Sociais do Brasil, ao se considerar que seus propósitos se apoiam no controle social e, para tanto, na divulgação das ações públicas por meio da informação e da transparência dos dados que muitas vezes não são publicados pelo governo local.

Conforme (Marteleto e Ribeiro, 1997 p. 3) "a falta de informações corretas dificulta às pessoas o acesso a realidade, ou seja, ao como e por que as coisas acontecem" e que a retenção ou a não publicação da informação dificulta o compartilhamento do saber de forma democrática (Marteleto e Ribeiro, 1997).

Além desses pressupostos, Albagli e Maciel (2004) destacam a relevância do conhecimento como capacidade de processar e recriar significados; e mais ainda, a capacidade de converter esse conhecimento em ação, ou, mais especificamente, em inovação.

Essa perspectiva evidencia a importância da produção de conhecimento desenvolvida pelas Redes dos Observatórios Sociais e das Cidades Justas e Sustentáveis ao atribuir a esse conhecimento possibilidades de ressignificação de saberes acerca da realidade vivida, "das experiências recriadas cotidianamente e na adversidade das situações que enfrentam" (Gohn, 2011, p.336). Decorrente desse contexto percebe-se que o conhecimento produzido ampliaria a noção sobre Gestão Social, uma vez que esta se vincula ao exercício da cidadania ancorado nas negociações de cunho participativo, dialógico ou de confronto entre os diversos atores sociais envolvidos, potencializando a reflexão sobre a produção de espaços socialmente construídos.

\section{Estratégias Metodológicas}

A investigação desenvolvida se inscreve no âmbito da pesquisa qualitativa, buscou-se por compreender de forma crítica, reflexividade e dialogal o conhecimento e a aprendizagem socioprática produzidos no âmbito do Observatório Social de Belém, tendo como foco as ações em prol de cidades justas, democráticas e sustentáveis e assumindo essa iniciativa como uma inovação social do campo da Gestão Social.

Destaca-se que o OSB foi escolhido, primeiramente, pela observância de suas práticas, as quais demonstram produção de conhecimento em Gestão Social ao contemplar a interseção e o diálogo com atores de campos diferentes, gerando informações e reflexão sobre as possibilidades e os desafios de cidades justas e sustentáveis. Esta noção pode ser percebida ao analisar o seu sítio eletrônico institucional e estudos bibliográficos sobre sua atuação.

A coleta de dados se deu por meio da pesquisa documental, oriunda das informações presentes no sítio eletrônico do Observatório Social de Belém (OSB), da Rede Social Brasileira por Cidades Justas, Democráticas e Sustentáveis, bem como do Observatório Social do Brasil. Além desta, nos meses de outubro e novembro de 2015 , foi realizada a observação não participativa em evento produzido pela Rede Social Nossa Belém, da qual se vincula o OSB, bem como no VI Colóquio "Organização, desenvolvimento e sustentabilidade", oferecido pelo Programa de Pós-Graduação em Administração (PPAD) da Universidade 
do Amazonas (UNAMA), cujas sessões desenvolvidas abordaram as perspectivas de desenvolvimento sustentável e o âmbito de atuação do OSB apresentado por um de seus integrantes.

Também foram coletados dados de natureza primária pela realização de entrevistas semiestruturadas em profundidade com atores envolvidas nessa iniciativa. Foram entrevistados dois membros do Conselho Administrativo do OSB, o presidente e o vice-presidente para assuntos institucionais e alianças. Procurouse, nesse processo, identificar e explorar: i) as ações conduzidas pelo OSB, tendo como foco a Gestão Social; ii) a ideia sobre cidades justas democráticas e sustentáveis preconizadas pelos agentes do OBS; iii) o grau de importância do diálogo e das interações sociais no desenvolvimento das práticas e articulações do OBS para a produção de conhecimento em Gestão Social.

\section{Produção de Conhecimento no Observatório Social de Belém}

O Observatório Social de Belém (OSB) foi criado em dezembro de 2010, por ocasião do Dia Internacional contra a Corrupção, com o estímulo de órgãos de controle como os Ministérios Públicos Estadual e Federal, a Polícia Federal, a Receita Federal e os Tribunais de Contas. Seguindo a diretriz da Rede Observatório Social do Brasil, o OSB se integrou ao Programa Estadual de Educação Fiscal na tentativa de mobilizar voluntários para se tornarem disseminadores do conceito de cidadania ativa, além de apontar caminhos aos participantes desse Programa para o exercício do controle social em prol de um país mais justo e sustentável (http://www.osdebelem.org).

Conforme apontado em seu site, O OSB vem buscando monitorar algumas licitações e identificar oportunidades de melhorias capazes de reduzir custos e aperfeiçoar o sistema de gestão municipal o que, em princípio, possibilita a redução de riscos e a ampliação da confiabilidade no alcance de seus resultados, independente da cor partidária (http://www.osdebelem.org).

O OBS se articula com outras redes sociais como a Rede de Observatório Social do Pará que conta com os Observatórios Sociais de Castanhal e de Abaetetuba. Além destes, o OSB se integra a Rede Nossa Belém que se vincula a Rede Social Brasileira por Cidades Justas, Democráticas e Sustentáveis, buscando apoiar, estimular, propor e executar ações que visem ao desenvolvimento justo e sustentável do município de Belém (http://www.osdebelem.org).

Ao tentar identificar e explorar as ações conduzidas pelo OSB, tendo como foco a Gestão Social, notou-se no cerne de seus propósitos congruência com as temáticas que envolvem a noção de cidadania sustentada pela participação democrática para o bem comum. Essa noção se expressa por meio de suas articulações com atores de diversos segmentos da sociedade civil em prol de interesses comuns vinculados a justiça e a sustentabilidade enquanto controle fiscal e destinação dos recursos financeiros do município de forma responsável e transparente.

Nesse sentido e, tomando como exemplo o Observatório Social de Maringá, o OSB apresenta duas linhas de ação, uma que é especificamente de prevenção voltada para o controle fiscal, por meio de processos de monitoramento de licitações e de checagens tradicional que os órgãos de controle do Tribunal de Contas fazem em conformidade com a lei. A outra se restringe ao fomento da educação fiscal cujo objetivo é estimular o cidadão para a importância de controlar o tributo pago e acompanhar a sua aplicação para fins sociais. Por fim, tem-se desenvolvido no escopo de sua atuação práticas apoiadas na ótica da sustentabilidade urbana e social ao se vincular como secretário executivo da Rede Nossa Belém, que trabalha com indicadores de gestão pública para a sustentabilidade (Presidente e Vice-presidente do Conselho Administrativo do OSB). Dessa forma, o OSB atua como controlador e fiscalizador das contas 
públicas, do patrimônio municipal e de pessoal, utilizando também os indicadores sociais apresentados pelas outras redes sociais a que estão associados.

O OSB mantém um convênio com a Rede Social Brasileira por Cidades Justas, Democráticas e Sustentáveis e um termo de cooperação com cidades sustentáveis com o intuito de ampliar as condições de monitoramento e avaliação da gestão de contas e de pessoas do município de Belém por meio dos indicadores sociais apresentados (Presidente e Vice-presidente do Conselho Administrativo do OSB).

Destaca-se que em 2013 o OBS passou a trabalhar com os indicadores referentes à mobilidade urbana e a resíduos sólidos, incentivados não só pela Rede de Cidades Justas e Sustentáveis, mas também pela Fundação Avina e pelo Projeto da sociedade civil sobre a sustentabilidade urbana, os quais investem em recursos financeiros e pessoal na busca por melhorias climáticas (Vice-presidente do Conselho Administrativo do OSB).

Segundo o Vice-presidente do Conselho Administrativo do OSB, ele e os demais voluntários, assim como o presidente, "fazem o que podem, pois são muitas propostas e atividades para poucas pessoas se mobilizarem e desenvolverem ações que de fato incidam na gestão pública e na sociedade" (Vice-presidente do Conselho Administrativo do OSB).

Somente nesta semana eu fui a cinco reuniões na Secretaria de Mobilidade Urbana de Belém para planejar e definir o plano de mobilidade do município. Em vez de controlar, eu fui convidado pela Secretária para fazer parte da comissão que está construindo o planejamento. Hora, eu estou executando (Vice-presidente do Conselho Administrativo do OSB)

Além de perceber que as finalidades e os processos de gestão do OBS se ancoram nos princípios da Gestão Social, nota-se que a trajetória profissional e de formação acadêmica dos voluntários também contribuem para ações de valor coletivo e de bem comum. Segundo o presidente do Conselho Administrativo, a sua atuação como servidor público demonstrou que suas atividades são insuficientes para fazer o órgão funcionar, de modo que, em um período ele se dedica ao trabalho e no outro ele fiscaliza, demandando serviço ao órgão público.

É a assunção de dupla responsabilidade que o servidor público tem. Uma de servidor que é remunerado para prestar serviço a população e outra como cidadão que deve colaborar com a coisa pública, acompanhando os financiamentos que são oriundos da contribuição social, uma vez que este nem sempre é para o bem coletivo (Presidente do Conselho Administrativo do OSB).

Nessa mesma vertente, o Vice-presidente do Conselho Administrativo do OSB disse que a sua experiência como professor acadêmico na área da geologia the proporcionou conhecimento sobre alguns domínios referentes a mobilidade urbana, campo de atuação do OSB em que mais atua.

Outro membro voluntário permanente tem formação e trajetória profissional no campo da estatística o que contribui diretamente para as atividades de monitoramento e de construção de indicadores sociais para o OSB. Os demais membros são oriundos de Programas de Pós-Graduação em Administração com ênfase em desenvolvimento sustentável e trabalham no apoio a conscientização e educação do controle fiscal e cidadão, seja por meio da produção científica acadêmica ou por meio da colaboração nas ações decorrentes do OSB. 
Outro ponto explorado a fim de analisar a produção de conhecimento sobre Gestão Social no âmbito do Observatório Social de Belém com foco em cidades justas e sustentáveis envolveu a ideia que eles têm sobre cidades justas e sustentáveis. Neste âmbito, tanto o Presidente do Conselho Administrativo como o Vice-presidente, compreendem que cidades justas e sustentáveis partem da premissa de se pensar em todos e, para isso, necessita de governança.

Hoje nós nos envolvemos com vários outros Observatórios, além dos nossos parceiros como a Fundação Avina, mas que trabalha mais na temática do clima. Eu observo que as pessoas veem os Observatórios somente como entidades de controle, mas não percebem o quanto nós atraímos as pessoas. É como fizemos aqui em Belém, nós tentamos trabalhar de forma que as pessoas tenham noção dos indicadores e da sua incidência para a cidade. Por isso que fizemos essas articulações com a Rede Nossa Belém e de Cidades Sustentáveis, para nos ajudar a discutir os indicadores junto com a população, sendo que estes são pensados em longo prazo, pois sabemos que eles não irão mudar de um dia para outro (Presidente do Conselho Administrativo do OSB).

Percebe-se, segundo o Presidente do Conselho Administrativo do OSB que o trabalho que eles desenvolvem segue um percurso de sustentabilidade ao se condicionar para um ciclo no qual há a mobilização das pessoas para o controle do tributo, há a demonstração de como controlar esse tributo e, ao final de um determinado período, há análise dos indicadores com o intuito de saber se eles foram alcançados ou não.

Entretanto, quando os entrevistados foram questionados sobre como eles observavam a noção que a população geral tem sobre a sustentabilidade e a justiça envolvendo as cidades, todos eles apontaram para uma ideia de descrédito e de modismo ou de algo muito complexo. Eles destacaram também que para as pessoas estes termos se expressam em benefício próprio. "Há o pensamento de que alguém tem que fazer por eles, que alguém tem que se responsabilizar por eles. Então não há o comprometimento por parte da população, e isso torna tudo mais simples, por que não eles precisam pensar" (Vice-presidente do Conselho Administrativo do OSB).

Infere-se que a compreensão que os membros do OBS desenvolvem sobre cidades justas e sustentáveis é convergente com as diretrizes que torneiam as suas atividades, uma vez que eles buscam uma articulação com diversos segmentos da sociedade civil, assumindo não só a busca pelo controle das contas públicas, enquanto justiça social, mas ações propositivas a partir da mediação entre governo público e sociedade civil, de forma a garantir resultados com base nos indicadores sociais. Essa perspectiva se traduz em sustentabilidade e justiça ao se apoiar na busca pelo direito à cidade. Duarte $(2015$, p.3) baseado nas proposições de Lefebvre (2008) identifica a cidade "como a luta pelo direito de criação e plena fruição do espaço social, compreendendo o exercício da cidadania efetivado pelo controle direto dos indivíduos sobre a forma de habitar a cidade". Nesse sentido, percebe-se a ideia de que a cidade deve ser vista "não como fragmentos, mas como um corpo político" (Harvey, 2009) e que, portanto, "pode ser produzida coletivamente a partir das ideias e ideais dos sujeitos que participam ativamente dessa produção, como espaço de materialização dos princípios de justiça social e ambiental" (Duarte, 2015, p.3).

A interação e o diálogo desenvolvido pelos membros do OSB com os diversos setores da população local foi outro ponto analisado a fim de subsidiar a análise da produção de conhecimento sobre Gestão Social. Gohn (2011, p.334) destaca que para analisar esses saberes, "deve-se buscar as redes de articulações que os movimentos estabelecem na prática cotidiana". Para a autora "essas redes são essenciais para compreender os fatores que geram as aprendizagens e os valores da cultura política que vão sendo 
construídos no processo interativo" (Gohn, 2011, p.334). Mediante esse aspecto notou-se uma aproximação e interação colaborativa e de respeito entre os membros do OSB com o governo local. Conforme o presidente e o vice-presidente do Conselho Administrativo do OBS, a organização social não se coloca contra o prefeito municipal.

Quando há fiscalização em uma licitação e percebemos alguma irregularidade, o primeiro a saber e a ser informado é o prefeito. Nós não anunciamos para fora, só ao prefeito primeiro. A gente parte do pressuposto da boa fé e nos queremos a solução do problema, então a gente não luta com a retirada do prefeito. A nossa relação é com o sistema, mesmo que com conflituosa (Presidente do Conselho Administrativo).

O empenho em se estabelecer uma relação com o Estado de corresponsabilidade sobre aquilo que é de interesse público (Pereira, 2010), foi perceptível também durante a reunião sobre resíduos sólidos promovida pelo OSB no qual contou com a participação de um membro da secretaria de saneamento básico de Belém e a associação dos catadores de lixo do município. Nesta reunião houve forte embate entre esses setores. De um lado, o representante do setor público, apresentando e explicando um projeto que se iniciou para ampliar e cuidar da coleta seletiva do lixo; e do outro lado, os catadores, reivindicando direitos constitucionais, como o apoio financeiro para o desenvolvimento de suas atividades, visto que eles "são os únicos que prestam serviço a população referente a seleção dos resíduos sólidos para reciclagem e com isso, contribuem diretamente para a sustentabilidade ambiental do município" (Presidente da Associação dos Catadores de Lixo de Belém). Os catadores também reivindicavam uma caçamba para retirada do lixo que sobrava depois que eles faziam a separação. Eles disseram que este lixo que se acumula contamina o solo.

Além de perceber uma nova relação entre Estado e Sociedade pautada no envolvimento de "múltiplos atores na gestão da cidade" (Pereira, 2010 p. 5), notou-se a importância do conhecimento dos atores presentes, não só para discutir de forma técnica a questão dos resíduos sólidos, mas para exercitar e ampliar as perspectivas de cidadania e de democracia menos representativa. Neste contexto, o mediador do OSB presente, demonstrou afinidade para com as necessidades dos catadores e com as dificuldades da prefeitura em atuar de forma mais rápida.

Hoje nos discutimos os indicadores de inclusão dos catadores de lixo. Os indicadores estão lá e eles não vão mudar de uma noite para o dia, mas nós estaremos lá amanhã para fiscalizar os contratos de lixo efetivados pela prefeitura com outras empresas, inclusive com os catadores. Vamos ver se efetivamente o governo vai ter recurso que execute essa inclusão (Presidente do Conselho Administrativo).

Acredita-se que interação entre catadores e prefeitura municipal, ainda que conflituosa e, por vezes divergente, produz conhecimento sobre Gestão Social ao promover espaço de diálogo e de confronto, incidindo na reflexão. Esse aspecto comunga com os preceitos da aprendizagem socioprática por ele se processar em meio a práticas compartilhadas e manifestadas nos comportamentos cotidianos.

Quanto ao diálogo que O OSB desenvolve com os demais setores sociais foi possível observar uma interação expressiva e de parceria bem significativa com a Controladoria Geral da União, com o Ministério 
Público Federal, Ministério Público da União e do Estado, bem como com o Tribunal de contas da União, "sendo esse último o mais forte para atuar na incidência e na atuação do controle dos tributos" (Presidente e Vice-presidente do Conselho Administrativo).

A origem do Observatório como o próprio nome diz é observar, mas a gente percebeu que isso é muito pouco. A gente tem que articular parceiros para ajudar a discutir. Hoje quando o Observatório faz uma atividade de diagnostico ele não trabalha sozinho, ele atua com entidades de interesse na área. Observamos que temos interesses comuns com o terceiro setor e com alguns órgãos públicos. Nesse aspecto o OSB tenta dialogar com todos para ajudar no controle social, por que hoje o controle do tributo é fiscalizado por órgãos públicos em que o dirigente é indicado pelo governador e assim, financiado por controles políticos partidários. Por isso que nós trabalhamos com a contribuição de pessoas apartidárias com o intuito de tornar o mais parcial possível esse controle (Presidente do Conselho Administrativo).

Segundo o Presidente do Conselho Administrativo, eles trabalham muito mais com a perspectiva da "esperança de mudar o que está ai".

Percebe-se que essas parcerias ancoradas pelo "interesse público sem coloração particular, mas expressos em indicadores técnicos e de percepção popular, qualificam tais movimentos a assumirem posições amplas e republicanas" (Pereira, 2010, p. 2). Tal contexto contribuiria para produção de conhecimento sobre Gestão Social.

Porém, quando argumentados sobre as interações dialógicas com os outros grupos sociais como os empresários e atores da sociedade civil, os entrevistados disseram que essas interações são muito pontuais e vão de acordo com os grupos de interesse. O Vice-presidente relatou que quando promove uma reunião para discutir algum ponto trabalhado pelo OSB ele costuma chamar, por e-mail, os colaboradores mais próximos. "É uma reunião menor, com pessoas que detém conhecimento técnico. Por exemplo, em reunião específica sobre a mobilidade urbana, um arquiteto leva uma tarefa e sua contribuição sobre o assunto discutido" (Vice-presidente do Conselho Administrativo). Ele ainda relatou que costuma enviar material e documentos sobre o assunto a ser abordado, por exemplo, em mesas redondas, forma de socialização e de integração que ele diz mais apreciar. Porém, poucos leem o material enviado, o que torna o diálogo menos qualificado (Vice-presidente do Conselho Administrativo).

Compreende-se que esse aspecto salienta o movimento cíclico sobre a informação, conhecimento e comunicação apontado por Marteleto e Ribeiro (1997), cujo processo de produção de conhecimento se torna concreto mediante o contato com informações corretas, de forma que essas se transformem em conhecimento e posteriormente em comunicação. Na situação relatada pelo Vice-presidente do Conselho Administrativo a falta de informação técnica interfere no diálogo e, consequentemente, na produção de conhecimento.

Ainda sobre a perspectiva de interação dialógica, o Presidente do Conselho Administrativo relatou que não há muita proximidade com a população mais vulnerável, a não ser com os catadores de lixo que são um grupo de interesse comum. Para ele, o fato desse segmento social lutar pela sobrevivência sobra 
pouco tempo para participarem de alguma ação social (Presidente do Conselho Administrativo). "Com os empresários ele disse que há pouca interlocução também, até porque, ao contrário do observatório de Maringá, que foi fundado por um grupo de empresários, O OSB foi fundado pela união de órgãos de servidores público e sociedade civil organizada" (Presidente do Conselho Administrativo).

Nota-se que as parcerias e interações sociais estão mais ligadas aos órgãos públicos de controle fiscal e a grupos de interesse como organizações da sociedade civil e estudantes acadêmicos, talvez pela proximidade profissional do Presidente e do Vice-presidente do Conselho Administrativo. Isto demonstra ser um desafio para a produção de conhecimento sobre Gestão Social do OSB. Motivar os demais setores sociais a participar das discussões e ações do Observatório, bem como levar a informação robusta e correta para um maior número de atores sociais de forma a tornar o diálogo mais consistente e reflexivo mostrou ser um limite para a produção de conhecimento sobre Gestão Social.

\section{Considerações Finais}

A análise da produção de conhecimento sobre Gestão Social no âmbito do Observatório Social de Belém com foco em cidades justas e sustentáveis apontou que as possibilidades de produção de conhecimento amparadas pelo processo socioprático de aprendizagem se enquadram em um contexto no qual a gestão pública brasileira está vivendo, cuja perspectiva é guiada pela participação de nos novos arranjos institucionais. Nesse âmbito, destacam-se as articulações em rede de uma organização da sociedade civil, o Observatório Social de Belém, como agente interlocutor dos interesses comuns da sociedade em prol de uma cidade mais justa e sustentável.

Foi possível perceber a sua importância no processo de participação social a partir do diálogo e das possibilidades de reflexão que contribui para a produção de conhecimento no âmbito da Gestão Social e, consequentemente, para ressignificação do direito a cidade ao considerá-la como lócus dialogal de construção social.

A informação clara e consistente por meio da socialização entre os atores envolvidos passa a ocupar lugar de destaque em suas práticas, seja por meio do controle fiscal ou por meio dos indicadores sociais com os quais trabalham. Esse processo de conversão da informação para o conhecimento e, posteriormente, para a comunicação demonstrou ser o cerne da produção de conhecimento no âmbito do Observatório Social de Belém. Contudo, demonstrou ser também um limite ao se perceber que, por vezes, a discussão entre os grupos se torna evasiva por falta de informações substanciais sobre o assunto a ser abordado, uma vez que o diálogo ou os confrontos são baseados nas experiências e nos saberes informais socializados, bem como no conhecimento formal e em dados reais. Esse cenário, indiretamente, limita a participação, dificultando a produção de conhecimento sobre Gestão Social.

Outra questão observada como um desafio é a falta de proximidade com alguns segmentos da população, como o empresarial e a sociedade civil vulnerável, reduzindo o seu campo de relações e de interações sociais.

Percebe-se que com poucos agentes e ferramentas já se fez muito por Belém ao se considerar os aspectos que envolvem a concepção de cidades justas e sustentáveis. Esse é um processo em constante construção e de descobertas que pode ser enriquecido e ampliado pelo conhecimento que vai sendo formado entre todos os envolvidos, conhecimento este que remete a noção de democratização, de direitos e de noção de sustentabilidade. Essas são temas relevantes, que trazem consigo possibilidades de futuras pesquisas associadas não somente ao conhecimento socioprático, mas a noção de reconfiguração da cidadania, da 
justiça socioambiental e da sustentabilidade a partir da interação entre sociedade civil e poder público, que vem sendo instaurada entre agentes de diferentes esferas sociais ao redor do mundo e também no âmbito da Amazônia.

No contexto amazônico, marcado por desafios e contradições importantes entre os ideários e as ações em prol do desenvolvimento e da sustentabilidade, da inovação e do resgate dos saberes dos povos tradicionais e das comunidades, o estudo de iniciativas que se propõem a construir uma gestão de territorialidades, no caso, a gestão de cidades, baseadas na produção de conhecimento e a aprendizagem socioprática em bases democráticas merecem mais estudos e análises. Para muitos, é no coração da Amazônia que novas transformações, realmente inovadoras, nas formas de se promover qualidade de vida, proteção do patrimônio ambiental, promoção das condições de vida, trabalho, renda e acesso ao bem-estar social, estão em ebulição. Os estudos no campo da Gestão Social não podem se furtar a isso, ficando todos os leitores convidados a "embarcar nessa Nau Social" em direção à complexidade das cidades e das territorialidades amazônicas em mais e mais investigações a partir dos achados da presente pesquisa.

\section{Referências:}

Abramovay, R. (2000, abr-jun). O Capital Social dos Territórios: repensando o desenvolvimento rural. Economia Aplicada. 4(2).

Agier, M. (2015, dez). Do Direito à Cidade ao Fazer-Cidade. O antropólogo, a margem e o centro. Mana, 21(3): p. 483-498.

Albareda, A. (2018) Connecting Society and Policymakers? Conceptualizing and Measuring the Capacity of Civil Society Organizations to Act as Transmission Belts. Voluntas, 29, p.1216-1232.

Albagli, S.; Maciel, M. L. (2004, set-dez). Informação e Conhecimento na Inovação e no Desenvolvimento Social. Ci. Inf. 33(3), 9-16, Brasília.

Allebrandt, S. L.; Marin Filho, C. J.; Ceratti, L. L. (2012). Gestão Social no Contexto de Políticas Públicas e Federais: leituras da experiência no território da cidadania noroeste colonial. In: Cançado et al (org.) Gestão Social: aspectos teóricos e aplicações. Ed. Unijui. ljui. 157-192.

Bauman, Z. (2008). A Sociedade Individualizada: vidas cotidianas e histórias vividas. Rio de Janeiro Ed. Jorge Zahar.

Chanlat, J. F. (2000). Ciências Sociais e Management: reconciliando o econômico com o social. São Paulo, Atlas.

Cançado, A. C; Tavares, B.; Dallabrida, V. R. (2013, set-dez). Gestão social e governança territorial: interseções e especificidades teórico-práticas. Revista Brasileira de Gestão e Desenvolvimento Regional, v. 9, n. 3, p. 313-353.

Carrion, R. S. M. (2008). O Desafio de Desenvolver Competências em Gestão Social: relato da experiência com a Residência Solidária/UFRGS. In: (Org) Silva JR, J. T. Gestão Social: Práticas em Debates, Teorias em Construção (Laboratório Interdisciplinar de Estudos em Gestão Social). Juazeiro do Norte: UFC.

Casimiro, L. M. S. M; Carvalho, H. (2021, jan-abr). Para cidades justas, em redes e inteligentes: uma agenda pública pelo direito à cidade sustentável. In: Núcleo de Pesquisa em Políticas Públicas e Desenvolvimento Humano (NUPED), PUCPR. International Journal of Digital Law, Belo Horizonte, ano 2, n.1, p. 199-2015. 
Castells, M. (1989). The informational city: Information technology, economic restructuring, and the urbanregional process, Oxford, Basil Blackwell [trad. esp.: La ciudad informacional: tecnologías de la información, reestructuración económica y el proceso urbano-regional, Madrid, Alianza, 1995].

(1977). The urban question: A marxist approach, Cambridge, ma, mit Press [trad. esp.: La cuestión urbana, Madrid, Siglo xxi, 1979].

Dowbor, L. (2016). O que é Poder Local? Imperatriz/MA: Ética.

Duarte, Marise Costa de Souza. (2015, jan-jun). O Direito à cidade e o direito às cidades sustentáveis no Brasil: o direito à procura e fruição do espaço e o enfrentamento do déficit de implementação. FIDES, 6(1), 15-33.

Fischer, T. M. (2002). Poderes locais, gestão e desenvolvimento. Salvador: Casa da Qualidade.

França-Filho, G. C. Definindo gestão social. (2008). In: Silva JR, J. T.; Mâsih, R. T.; Cançado, A. C.; Schommer, P. C. Gestão Social. Práticas em debate, teorias em construção, p. 26-37. Juazeiro do Norte CE, Liegs/UFC.

Freire, P. (1987). Pedagogia do Oprimido. Rio de Janeiro: Paz e Terra.

Gianella, V. (2018, mai-out) Perspectivas e desafios da participação em tempos de crise democrática. Revista NAU Social, v.09, n.16, p. 91-106.

Gohn, M. G. (2011, mai-ago). Movimentos Sociais na Contemporaneidade. Revista Brasileira de Educação, 16(47), p. 333-361.

São Paulo: Cortez.

(2008) O protagonismo da sociedade civil: movimentos sociais, ONGs e redes solidárias. 2. ed. (2004, mai-ago). Empoderamento e participação da comunidade em políticas públicas. Saúde e Sociedade, 13(2), p. 20-31.

Harvey, D. (2009). Conferência proferida no Seminário "Lutas pela reforma urbana: o direito à cidade como alternativa ao neoliberalismo". Fórum Social Mundial.

. (2008) The Right to the City. New Left Review, 53, p. 23-40.

(1982). The limits to capital, Oxford, Basil Blackwell.

Kornberger, M.; Carter, C. (2010) Manufacturing competition: how accounting practices shape strategy making in cities. Accounting, Auditing \& Accountability Journal, v. 23, n. 3, p. 325-349.

Lave, J. e Wenger E. (1991). Situated learning: legitimate peripheral participation. New York: Cambridge University Press, $11^{\mathrm{a}}$ reimpressão.

Lefebvre, H. (1970). A revolução urbana. Trad. MARTINS, S. Belo Horizonte: Editora UFMG 1999.

Espaço e Política. Trad. de ANDRADE, Margarida Maria e MARTINS, Sérgio. Belo Horizonte: Editora UFMG, 2008.

Lüchmann, L. H. H.; Schaefer, M. I.; Nicoletti, A. S. (2017) Associativismo e Repertórios de Ação PolíticoInstitucional. Opinião Pública, Campinas, vol. 23, nº 2, maio-agosto, p. 361-396.

Machado, J. A. (2007). Ativismo em rede e conexões identitárias: novas perspectivas para os movimentos sociais. Sociologias, ano 9 (18), p. 248-285.

Marteleto, R. M; Ribeiro, L. B. (1996/1997). Informações e Construção do Conhecimento para a Cidadania no Terceiro Setor. Projeto Integrado de Pesquisa, "Cultura, Informação e Sociedade; estudo das práticas de 
informação em campos sociais específicos com vistas à revisão e ampliação de modelos de comunicação e transferência da informação". Financiamento CNPQ.

Melucci, Alberto. (1996). Challenging codes. Cambridge: Cambridge University Press.

Moraes, R. L.; Andion, C. (2018) Civil Society and Social Innovation in Public Arenas in Brazil: Trajectory and Experience of the Movement Against Electoral Corruption (MCCE). Voluntas, 29, p. 801-818.

Nonaka, I \& Takeuchi, H. (1997). Criação de conhecimento na empresa. Rio de Janeiro: Campus.

Observatório Social de Belém. http://www.osdebelem.org. Acessado em set/2015.

Pereira, M. B. (2010). A Rede Social Brasileira por Cidades Justas, Democráticas e Sustentáveis. www.nossasaopaulo.org.br/portal/arquivos/artigoRedeCidades.pdf. Acessado 28/11.

Pleyers, G. Movimentos Sociales en el siglo XXI: perspectivas y herramientas analíticas. Ciudad Autónoma de Buenos Aires : CLACSO.

Porta, D. D. (2020) Building Bridges: Social Movements and Civil Society in Times of Crises. Voluntas, 31, p. 938-948.

Schommer, P. C.; Boullosa, R. F. (2010). Com quantas andorinhas se faz um verão? Práticas, relações e fronteiras de aprendizagem. In: Schommer, P. C., Santos, I. G. Aprender se aprende aprendendo: construção de saberes na relação entre universidade e sociedade. Salvador: CIAGS/UFBA, FAPESB;SECTI; CNPQ, 18-41.

Schommer, P. C. \& França-Filho, G. C. (2008). Gestão Social e aprendizagem em comunidades de práticas: interações conceituais e possíveis decorrências em processo de formação. In Laboratório Interdisciplinar de Estudos em Gestão Social. Gestão Social: Práticas em Debates, Teorias em Construção. Juazeiro do Norte - CE: Universidade Federal do Ceará.

Santos, B. S. (2007, nov.) Para Além do Pensamento Absissal: Das linhas globais a uma ecologia de saberes. Novos Estudos, CEBRAP, p. 71-94.

Santos, B. S. (2006) Renovar la teoría crítica y reinventar la emancipación social (encuentros en Buenos Aires). Buenos Aires: CLACSO.

Sassen, S. (2007, set-dez). Una Sociología da La Globalización. Analisis Político, 61, 3-27. Bogotá.

Silva, S. L. (2004, mai-ago). Gestão do Conhecimento: uma revisão crítica orientada pela abordagem da criação do conhecimento. Ci. Inf. 33(2), p. 143-151.

Spink, M. J.; Spink, P. (2017, dez.) Pesquisar o/no cotidiano na pesquisa social: reflexões sobre a noção de lugar, território e redes de associação. Quaestio, Sorocaba, SP, v. 19, n. 3, p. 591-605.

Tenório, F. G. (1999). Um espectro ronda o terceiro setor: o espectro do mercado. Revista de Administração Pública, 33(5) p. 85-102.

Tenório, F. G.; Dutra, J. L. A.; Magalhães, C. M. R. (2004). Gestão social e desenvolvimento local: uma perspectiva a partir da cidadania deliberativa. In: ENANPAD, 28. Curitiba: Anpad. CD-ROM.

Vargas, A. L. B.; Guedes, C. A. M. (2021, nov-abr) Controle social e desenvolvimento na perspectiva da Gestão Social e do Bem Viver: estudos de casos na Argentina, Brasil, Chile e Equador. Revista NAU Social, v.12, n.22, p. $461-477$. 